\title{
Neck circumference is independently associated with relative systemic hypertension in young adults with sickle cell anaemia
}

\author{
Lawrence A. Olatunji ${ }^{1 *}$, Olatunde P. Olabode ${ }^{1}$, Olawale M. Akinlade ${ }^{1,2}$, Abiola S. Babatunde $^{3}$, \\ Victoria A. Olatunji ${ }^{4}$ and Ayodele O. Soladoye ${ }^{1}$
}

\begin{abstract}
Background: A seemingly interesting observation in patients with sickle cell anaemia (SCA) is that they usually have lower systemic blood pressures (BP) and insulin resistance than persons in the general population in spite of chronic inflammation and vasculopathy. However, relative systemic hypertension (rHTN) has been linked to pulmonary hypertension, increased blood viscosity and renal insufficiency, which could indicate a risk of developing cardiometabolic disorder (CMD) in SCA.

We therefore hypothesized that neck circumference (NC) and CMD marker; triglyceride glucose (TyG) index would independently predict rHTN in young adults with SCA in steady state.
\end{abstract}

Methods: We compared the anthropometrical, hematological, hemorheological and CMD markers between SCA patients with normal BP < 120/70 mmHg; nHTN, $n=65)$ and those with rHTN (BP $\geq 120 / 70 \mathrm{mmHg}, n=32)$.

Results: Our results showed that SCA with rHTN had significantly higher body weight, waist circumference, NC, plasma viscosity, systolic and diastolic BP. Results also indicated that NC (OR: 2.98; 95\% Cl 1.46 to $6.10, p<0.01$ ) was a predictor of rHTN in SCA independent of gender, age, weight, waist circumference, BMI, blood viscosity, triglyceride or TyG. A receiver operating characteristic curve analysis also showed that NC was the most efficient predictor of rHTN than other CMD markers.

Conclusion: The present study demonstrates that increased NC is a salient risk factors that is independently associated with rHTN in SCA. The finding therefore underscores the utility of NC in early detection and stratification of systemic hypertension, particularly in individuals with SCA.

Keywords: Arterial blood pressure, Cardiometabolic disorder, Neck circumference, Sickle cell disease, Upper-body fat accumulation

\section{Background}

Sickle cell disease (SCD), one of the most common inherited blood disorders worldwide, is an autosomal recessive disorder caused by point mutations in the gene that encodes the $\beta$-globin chains of hemoglobin $(\mathrm{Hb})$, leading to polymerization of erythrocytes upon deoxygenation. This

\footnotetext{
* Correspondence: tunjilaw04@yahoo.com

${ }^{1}$ HOPE Cardiometabolic Research Team and Department of Physiology, College of Health Sciences, University of Ilorin, P.M.B 1515, Ilorin, Kwara State 240003, Nigeria

Full list of author information is available at the end of the article
}

in turn, results in rigid, adherent erythrocytes, which get trapped in the microcirculation. Vaso-occlusive phenomena and hemolysis are the clinical hallmarks, although other clinical occurrences are also observed [1]. This group of individuals with advanced age, could develop chronic inflammation-related organ injury, such as chronic kidney disease (CKD), atherothrombotic events, pulmonary vasculopathy or hypertension $[2,3]$.

Individuals with sickle cell anemia (SCA) have been shown to have lower arterial BP when compared with age- and sex-matched persons without SCA $[4,5]$, but 
fail to show the age related rise in BP common in the normal population. The prevalence of systemic hypertension is also lower in SCA [6]. The findings that patients with SCA have low BP seems to counter recent pathophysiological studies which suggest that these patients develop endothelial dysfunction and arterial vasculopathy associated with reduced nitric oxide (NO) bioavailablity that is seen in the hypertensive population $[7,8]$. Also, even within a range of systolic and diastolic BP that would be considered normal by conventional standards in SCA, there is an association between increased BP and cerebrovascular accident or mortality $[4,6,9]$. These reports raise the possibility that the normal range for BP in patients with SCA appears to be higher than it might have been expected, given the severity of their anemia, vasculopathy and exacerbated organ damage. This suggests the likelihood of relative systemic hypertension in these patients (rHTN) [6].

Sickle cell disease is an independent cause of pulmonary artery hypertension and patients with SCD have been reported to have increased risk to develop pulmonary hypertension and renal dysfunction than the normal control [2]. Pulmonary hypertension has been associated with reduced survival in SCD patients $[6,9]$. Also elevated systemic blood pressures had been shown to contribute significantly to left ventricular diastolic dysfunction, a phenomenon which has been reported as an independent predictor of death in SCD patients $[6,9]$. Systemic hypertension is a major risk factor for cardiovascular disease (CVD) estimated to account for about 9.4 million deaths in 2010 with global prevalence in adults of about $22 \%$ in 2014 [10]. Interestingly, a group of investigators has established that $\mathrm{BP} \geq 120 / 70 \mathrm{mmHg}$ considerably increased the risk for atherothrombotic CVD and chronic organ injury in these individuals [2]. Early recognition and prompt treatment of relative systemic hypertension in young adults with SCD may inhibit progression to pulmonary hypertension, renal dysfunction and other cardiovascular complications thereby reducing morbidity in affected individuals.

Overweight and obesity are rising to pandemic and remain major public health problems globally and they are important risk factor for cardiometabolic disorder (CMD). The prevalence of obesity varies from 10 to $40 \%$ in different populations [11, 12]. Unfortunately, the prevalence of obesity has increased in industrialized countries and also in developing ones, including Nigeria, where there is high incidence and prevalence of SCA [13]. Several recent studies have shown that upper-body subcutaneous fat appears to confer additional risk for CMD than general and central obesity, which has been reliably predicted by the neck circumference (NC). NC is strongly correlated with insulin resistance (IR) and other CMD risk factors across several ethnicities in the general population [14-17]. Moreover, there is a growing interest in the utility of a simple but reliable marker with wide applicability; the triglyceride-glucose (TyG) index, the product of the fasting blood glucose and triglyceride (TG) levels for IR $[18,19]$.

Since upper-body fat accumulation may be responsible for many hormonal changes playing a role in the development of cardiovascular dysfunction and HTN in the general population, we suggest that it could be the case in SCA patients too. To the best of our knowledge to date, there have been no published studies on the association between the indices of IR and upper-body visceral adiposity, using NC or TyG in young adults with SCA. In this study, we therefore tested the hypothesis that $\mathrm{NC}$ and TyG index would independently predict rHTN in young adults with SCA in steady state.

\section{Methods}

\section{Study population}

The study was carried out in the adult outpatient sickle cell clinics of the University of Ilorin Teaching Hospital (UITH), Ilorin, Kwara State, Nigeria and Ladoke Akintola University of Technology (LAUTECH) Teaching Hospital, Ogbomoso, Oyo State, Nigeria between February, 2013 and April 2016, and included $97(\mathrm{M} / \mathrm{F}=50 / 47)$ young adults who had $\mathrm{Hb}$ genotype SS confirmed by $\mathrm{Hb}$ electrophoresis. All patients were in steady-state condition at the time recruitment into the study which was defined as absence of vaso-occlusive crisis, acute chest syndrome (ACS), stroke, priapism, and absence of any signs or symptoms attributed to acute illness, at least 8 weeks before inclusion into the study. The exclusion criteria for SCA patients were presence of congenital or acquired heart disease, pregnancy, very severe anemia (hematocrit $<18 \%$ ), blood transfusions in the previous 12 weeks, use of drugs that modifies blood rheology, excessive intake of alcohol (more than $16 \mathrm{~g}$ daily), and use of tobacco. All patients were informed about the purpose and procedures of the study, and gave their written consent. The study was conducted in accordance with the guidelines set by the Declaration of Helsinki on the protection of the rights of human subjects and was approved by the Ethical Review Committees of UITH and LAUTECH Teaching Hospital.

\section{Clinical parameters}

Waist circumference (WC), neck circumference (NC), hip circumference $(\mathrm{HC})$, height and weight were measured for all patients using a meter tape and body mass index (BMI) was calculated as BMI $=$ weight $/$ height $^{2}, \mathrm{Kg} /$ $\mathrm{m}^{2}$, triglyceride-glucose index was estimated as the product of fasting triglyceride and glucose expressed as TyG index; Ln [TG (mg/dl)* FPG (mg/dl)/2] [18] whereas TyG-BMI; TyG*BMI, TyG-WC; TyG*WC [Er 
et al., 2016]. The blood pressures of subjects were measured using the auscultatory method of Korotokoff. At the clinics, patients were made to seat comfortably in a chair with the upper arm rested on a table for 3 min before measurement of the blood pressures. Using a mercury in-glass Shygmomanometer and appropriate cuff was applied to the upper arm with the lower edge of the cuff at least one inch above the antecubital fossa. The approximate systolic blood pressures were first obtained for each patient by inflating the cuff and palpation of the brachial artery. The cuff was then deflated and reinflated to about $10 \mathrm{mmHg}$ above the approximate systolic pressure value. The cuff was then deflated and the systolic and diastolic blood pressures of the patients were recorded as the phase I and phase IV Korotokoff sounds respectively. Repeated 3 blood pressure measurements were taken after 10 min interval in each patient and recorded. The blood pressure values of the subjects were then recorded as average readings of the systolic and diastolic blood pressures. The BP values $<120 / 70 \mathrm{mmHg}$ were considered as normal (nHTN group; $n=65$ ). Patients with $\mathrm{BP}$ values $\geq 120 / 70 \mathrm{mmHg}$ and $<140 / 90 \mathrm{mmHg}$ were considered as having rHTN $(n=29)$; patients with BP levels $\geq 140 / 90 \mathrm{mmHg}$ had hypertension (HTN) $(n=3)$ [2]. Mean arterial pressure (MAP) was calculated for the two groups as the diastolic $\mathrm{BP}+1 / 3$ pulse pressure. Heart rate $(\mathrm{HR})$ was also measured for each patient.

\section{Biological parameters}

Blood samples were drawn after a $12 \mathrm{~h}$ overnight fasting, between 8:00 a.m. and 10:00 a.m. For hematological parameters such as $\mathrm{Hb}$ and hematocrit (Hct) concentrations; red blood cell (RBC), white blood cell (WBC) and platelet (PLT) counts were determined using automated blood cell counter (Mandray automated machine, model BC5300/ RD28103112). Remaining blood samples were centrifuged at $3000 \mathrm{rpm}$ for $15 \mathrm{~min}$ and plasma was stored frozen until used for biochemical assay. Measurements of plasma glucose and triglycerides (TG) were performed using standard biochemistry and the plasma viscosity was measured by simple viscometer technique, based on the rate of flow; blood viscosity was also measured.

\section{Statistical analysis}

Results are presented as means \pm standard deviation (SD). Unpaired Student's t-test was used for continuous covariates, to compare biological parameters between the different groups. To identify risk factors associated with HTN in SCA patients, we used a binary (i.e., presence or absence of HTN) multivariate logistic model and ROC curve analysis. Significance level was defined as $p<0.05$. Statistical analyses were done using SPSS (version 16, IBM SPSS Statistics, Chicago, IL).

\section{Results}

The number of patients with nHTN $(n=65)$, rHTN $(n=29)$; patients with BP levels $\geq 140 / 90 \mathrm{mmHg}$ had hypertension (HTN) $(n=3)$ [2]. However, because of the limited number of patients in the latter group, the two groups with either rHTN or HTN were pooled to create a single group (rHTN group; $n=29+3=32$ ). The clinical characteristics of the study population classified according to the presence or absence of rHTN are summarized in Table 1. The rHTN group had higher weight, WC and $\mathrm{NC}$ when compared to those of the nHTN group. However, mean values for age, height, $\mathrm{BMI}$ and NC of the two groups were not statistically different (Table 1).

Table 2 shows the hematological and hemorheological parameters between SCA patients with rHTN and SCA patients without rHTN. Plasma viscosity was increased in the rHTN group when compared with that of the nHTN group $(p<0.05)$, whereas RBC, WBC, PLT counts as well as $\mathrm{Hb}$, Hct and blood viscosity values in rHTN group were not significantly different from those of the nHTN groups (Table 2).

Figure 1 depicts mean values for blood pressure and heart rate in rHTN and nHTN groups. Mean values of SBP, DBP and MAP were significantly higher in the rHTN group than in the nHTN group. However, no difference was observed for HR mean values between the groups.

Table 3 summarizes the mean values of CMD markers in both rHTN and nHTN groups. FPG, TG, TyG index and TyG-WC were not significantly different between the two groups. However, TyG-BMI was significantly associated with rHTN.

A binary multivariate logistic model (Table 4) was used to identify risk factors associated with rHTN in SCA patients and included WC, NC, BMI, Hct, plasma viscosity, blood viscosity and TyG index. The overall model was

Table 1 Anthropometric data of the sickle cell anemia (SCA) patients classified according to hypertension status

\begin{tabular}{llll}
\hline Parameters & $\mathrm{nHTN}$ & $\mathrm{rHTN}$ & $P$ \\
\hline Age (years) & $20.6 \pm 5.5$ & $23.6 \pm 9.3$ & 0.094 \\
Gender $(\mathrm{M} / \mathrm{F})$ & $30 / 35$ & $20 / 12$ & \\
Weight $(\mathrm{kg})$ & $46.9 \pm 9.1$ & $52.5 \pm 13.2$ & 0.016 \\
Height $(\mathrm{m})$ & $1.6 \pm 0.1$ & $1.6 \pm 0.1$ & 0.123 \\
BMl $\left(\mathrm{kg} / \mathrm{m}^{2}\right)$ & $19.2 \pm 10.5$ & $22.5 \pm 13.9$ & 0.202 \\
WC $(\mathrm{cm})$ & $73.7 \pm 7.1$ & $76.9 \pm 7.7$ & 0.048 \\
NC $(\mathrm{cm})$ & $31.9 \pm 2.1$ & $34.1 \pm 1.7$ & 0.001 \\
Hip $(\mathrm{cm})$ & $84.6 \pm 8.7$ & $87.3 \pm 10.6$ & 0.187 \\
\hline
\end{tabular}

Means \pm SD. nHTN No relative systemic hypertension with blood pressure values < 120/70 mmHg; $r H T N$ Relative systemic hypertension patients with blood pressure values $\geq 120 / 70 \mathrm{mmHg}$; BMI Body mass index; WC Waist circumference; NC Neck circumference. Significant difference $(p<0.05)$ 
Table 2 Hematological and hemorheological profile of the sickle cell anemia (SCA) patients classified according to hypertension status

\begin{tabular}{llll}
\hline Parameters & $\mathrm{nHTN}$ & $\mathrm{rHTN}$ & $p$ \\
\hline RBC $\left(10^{12} / \mathrm{L}\right)$ & $3.2 \pm 0.8$ & $3.1 \pm 0.7$ & 0.353 \\
WBC $\left(10^{9} / \mathrm{L}\right)$ & $9.3 \pm 3.3$ & $9.7 \pm 4.5$ & 0.605 \\
Platelet $\left(10^{9} / \mathrm{L}\right)$ & $339.8 \pm 143.0$ & $325.4 \pm 183.5$ & 0.675 \\
Hemoglobin $(\mathrm{g} / \mathrm{L})$ & $48.3 \pm 39.5$ & $47.9 \pm 42.8$ & 0.966 \\
Hematocrit $(\%)$ & $25.5 \pm 5.9$ & $25.5 \pm 5.3$ & 0.995 \\
Plasma viscosity & $2.1 \pm 0.3$ & $2.3 \pm 0.4$ & 0.004 \\
Blood viscosity & $4.9 \pm 1.8$ & $5.3 \pm 1.5$ & 0.254 \\
\hline
\end{tabular}

Means \pm SD. $n H T N$ No relative systemic hypertension with blood pressure values $<120 / 70 \mathrm{mmHg}$; $r$ TTN Relative systemic hypertension patients with blood pressure values $\geq 120 / 70 \mathrm{mmHg} ; R B C$ Red blood cell count; $W B C$ White blood cell count. Significant difference $(p<0.05)$

statistically significant (chi-square $=30.38 ; \quad \mathrm{df}=7 ; \quad p<$ 0.001 ), however only two parameters included in the model were significantly associated with rHTN: NC (OR: $4.21 ; 95 \%$ CI 1.35 to $13.18, p=0.013$ ) and TyG index (OR: 7.09; 95\% CI 1.38 to $36.57, p=0.019$ ). A second model, MODEL 2 adjusted for Hct, plasma viscosity and blood viscosity was still significant (chi-square $=$ 19.44; $\mathrm{df}=4 ; p<0.001)$ and retained the same significant parameters as in MODEL 2: NC (OR: 2.36; 95\%CI 1.36 to $4.11, p=0.002)$ and TyG index (OR: $3.90 ; 95 \% \mathrm{CI} 1.01$
Table 3 Cardiometabolic disorder markers of the sickle cell anemia (SCA) patients classified according to hypertension

\begin{tabular}{llll}
\hline & nHTN & rHTN & $p$ \\
\hline FPG $(\mathrm{mmol} / \mathrm{L})$ & $4.1 \pm 1.5$ & $4.3 \pm 1.3$ & 0.617 \\
TG $(\mathrm{mmol} / \mathrm{L})$ & $1.0 \pm 0.5$ & $1.1 \pm 0.4$ & 0.255 \\
TyG index & $7.9 \pm 0.6$ & $8.2 \pm 0.6$ & 0.162 \\
TyG-BMI & $151.7 \pm 20.4$ & $184.5 \pm 28.0$ & 0.044 \\
TyG-WC & $597.1 \pm 70.7$ & $638.7 \pm 96.1$ & 0.088 \\
\hline
\end{tabular}

Means \pm SD. nHTN No relative systemic hypertension with blood pressure values $<$ 120/70 mmHg; rHTN Relative systemic hypertension patients with blood pressure values $\geq 120 / 70 \mathrm{mmHg}$; FPG Fasting plasma glucose; TG Triglycerides; TyG index The product of triglycerides and fasting glucose; BMI Body mass index; WC Waist circumference; TyG-BMI, TyG*BMl; TyG-WC, TyG*WC

to $15.08, p=0.048)$. A third model, MODEL 3 adjusted for $\mathrm{WC}$ was also significant (chi-square $=17.76$; $\mathrm{df}=3 ; p$ $<0.001$ ). In MODEL 4, when MODEL 3 was adjusted for BMI; the overall model was statistically significant (chi-square $=19.02 ; \mathrm{df}=3 ; p<0.001$ ), however only $\mathrm{NC}$ was significantly associated with rHTN: NC (OR: 2.25; 95\%CI 1.34 to $3.78, p=0.002$ ). In MODEL 5 , when MODEL 3 was adjusted for both WC and BMI; the overall model was statistically significant (chi-square $=17.68$; $\mathrm{df}=2 ; p<0.001)$, both $\mathrm{NC}$ and TyG were significantly associated with rHTN: NC (OR: 2.11; 95\% CI 1.32 to $3.38, p<0.002)$ and TyG index (OR: $4.09 ; 95 \% \mathrm{CI} 1.10$ to
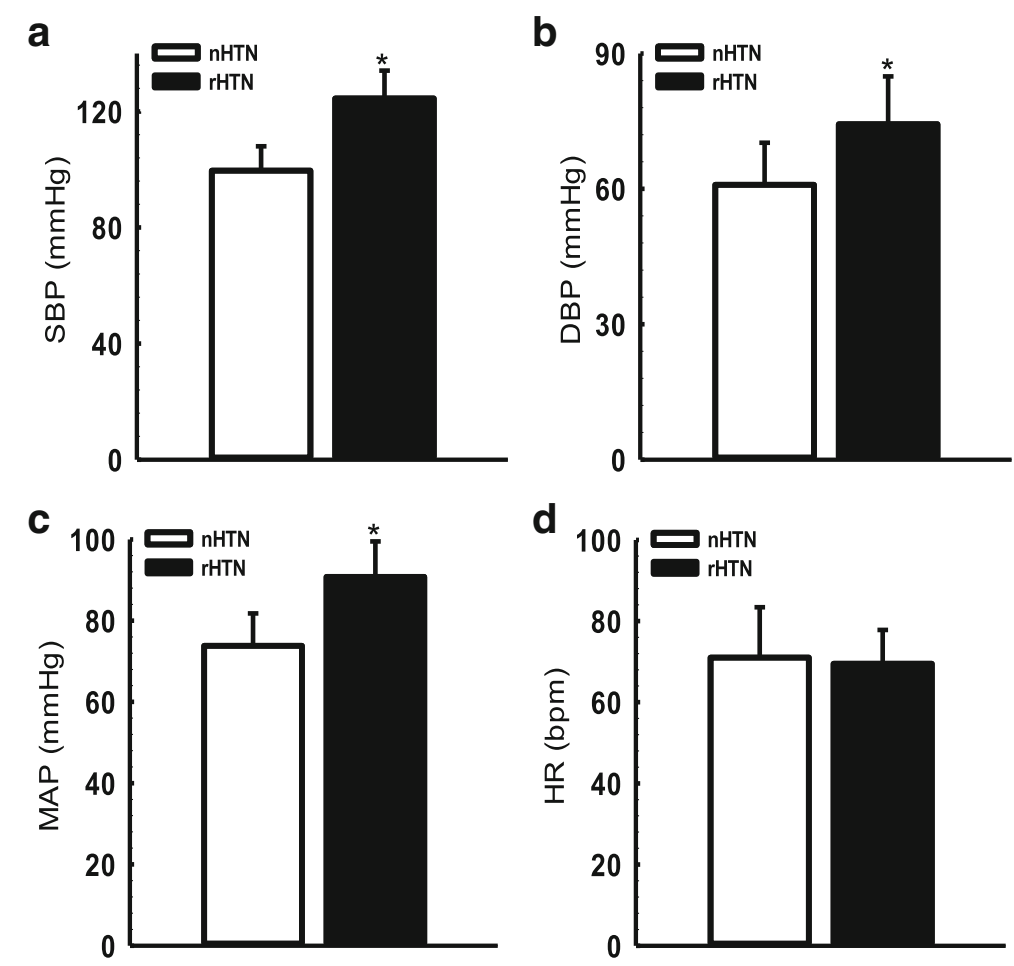

Fig. 1 Blood pressure and heart rate of the SCA patients classified according to hypertension nHTN, no relative systemic hypertension with blood pressure values < 120/70 mmHg; rHTN, relative systemic hypertension patients with blood pressure values $\geq 120 / 70 \mathrm{mmHg}$; SBP, systolic blood pressure (a); DBP, diastolic blood pressure $(\mathbf{b})$; MAP, mean arterial pressure $(\mathbf{c})$; HR, heart rate $(\mathbf{d})$. Significant difference $\left({ }^{*} p<0.01\right)$ 
Table 4 Association between neck circumference (NC), the product of triglycerides and fasting glucose(TyG) index and relative systemic hypertension ( $\mathrm{rHTN}$ ) in sickle cell anemia (SCA) patients

\begin{tabular}{|c|c|c|c|c|c|c|}
\hline \multicolumn{4}{|l|}{$\mathrm{NC}$} & \multicolumn{3}{|c|}{ TyG index } \\
\hline & OR & $95 \% \mathrm{Cl}$ & $p$ & $\mathrm{OR}$ & $95 \% \mathrm{Cl}$ & $p$ \\
\hline MODEL 1 & 4.21 & $1.35-13.18$ & 0.013 & 7.09 & $1.38-36.57$ & 0.019 \\
\hline MODEL 2 & 2.36 & $1.36-4.11$ & 0.002 & 3.90 & $1.01-15.08$ & 0.048 \\
\hline MODEL 3 & 2.16 & $1.31-3.56$ & 0.003 & 4.22 & $1.11-16.10$ & 0.035 \\
\hline MODEL 4 & 2.25 & $1.34-3.78$ & 0.002 & 3.69 & $0.98-13.85$ & 0.053 \\
\hline MODEL 5 & 2.11 & $1.32-3.38$ & 0.002 & 4.09 & $1.10-15.23$ & 0.036 \\
\hline MODEL 6 & 1.86 & $1.22-2.81$ & 0.004 & & & \\
\hline MODEL 7 & & & & 2.22 & $0.76-6.87$ & 0.168 \\
\hline
\end{tabular}

15.23, $p=0.036)$. In MODEL 6, when MODEL 5 was adjusted for TyG; the overall model was statistically significant (chi-square $=12.11 ; \mathrm{df}=1 ; p<0.001$ ), and $\mathrm{NC}$ was significantly associated with rHTN: NC (OR: 1.86; 95\% CI 1.22 to 2.81, $p=0.004$ ); however, when MODEL 5 was adjusted for $\mathrm{NC}$ in MODEL 7; the overall model was not statistically significant and the association between TyG and rHTN was lost.

To determine the relevance of each variables for predicting rHTN, the receiver operating curve (ROC) was plotted and the area under the curves (AUCs) were compared (Table 5). The AUC derived for NC was significantly larger than all other variables. For variable that

Table 5 Area under the receiver operating characteristic (ROC) curve in sickle cell anemia (SCA) patients with relative systemic hypertension (rHTN)

\begin{tabular}{|c|c|c|c|c|}
\hline & $\mathrm{rHTN}$ & & & \\
\hline & Area & SE & $95 \% \mathrm{Cl}$ & $P$ \\
\hline Age & 0.580 & 0.093 & $0.397-0.762$ & 0.371 \\
\hline Weight & 0.708 & 0.102 & $0.509-0.908$ & 0.019 \\
\hline BMI & 0.512 & 0.084 & $0.368-0.776$ & 0.324 \\
\hline WC & 0.547 & 0.098 & $0.355-0.740$ & 0.594 \\
\hline $\mathrm{NC}$ & 0.809 & 0.069 & $0.673-0.944$ & 0.001 \\
\hline $\mathrm{Hb}$ & 0.561 & 0.084 & $0.396-0.725$ & 0.495 \\
\hline $\mathrm{Hct}$ & 0.703 & 0.079 & $0.547-0.858$ & 0.023 \\
\hline Plasma viscosity & 0.602 & 0.084 & $0.438-0.767$ & 0.250 \\
\hline Blood viscosity & 0.667 & 0.077 & $0.515-0.818$ & 0.061 \\
\hline TyG index & 0.644 & 0.085 & $0.478-0.810$ & 0.105 \\
\hline TyG-BMI & 0.580 & 0.110 & $0.364-0.795$ & 0.371 \\
\hline TyG-WC & 0.602 & 0.096 & $0.415-0.790$ & 0.250 \\
\hline
\end{tabular}

rHTN Relative systemic hypertension patients with blood pressure values $\geq 120 /$ $70 \mathrm{mmHg}$; BMI Body mass index; WC Waist circumference; NC Neck circumference; $\mathrm{Hb}$ Hemoglobin; Hct Hematocrit; TyG index The product of triglycerides and fasting glucose; TyG-BMI, TyG*BMl; TyG-WC, TyG*WC; SE Standard error; Cl Confidence interval was significantly associated, NC had the largest AUC (0.809), followed by weight (0.708) and Hct (0.703).

\section{Discussion}

To the best of our knowledge, this is the first study that investigated the associations between increased $\mathrm{NC}$ and the risk of development of relative systemic elevated $\mathrm{BP}$ among young individuals with SCA. Multivariate logistic regression and ROC curve analyses of our data showed significant association between increased $\mathrm{NC}$ and the risk of rHTN among young adults with SCA. The present study demonstrates for the first time that $\mathrm{NC}$ is independently associated with rHTN in young adults with SCA independent of cardiovascular and metabolic risk factors.

Cardiovascular and metabolic disorders are inextricably linked and are the leading causes of mortality and morbidity in both sexes worldwide. IR is considered to be a critical metabolic link of the cardiometabolic disorder, with incidence and prevalence rapidly increasing worldwide over the last decade despite increased efforts to prevent and control. IR occurs in $20 \%-25 \%$ of the human population [20] and it is the hallmark of both the prediabetic state and overt type 2 diabetes [21]. Although the incidence of IR, type 2 diabetes, obesity, and CMD is considered rare in SCA; there is however a few reported cases [22, 23]. Because of the clinical as well as public health importance of IR, the ability to identify otherwise healthy normal weight non-obese individuals with IR before the development of CMD is of paramount importance, particularly in SCA patients.

The concept that some non-obese individuals present with several risk factors for CMD and represent one end of the spectrum of obesity was first proposed by Ruderman et al. $~ 30$ years ago [24]. Ongoing investigations reveal that individuals that are metabolically obese but have normal weight (MONW), termed 'metabolically abnormal normal weight' or 'normal weight obese', are not uncommon [25, 26]. They are characterized by the increased levels of adiposity and IR, and a higher susceptibility to CMD [25]. Furthermore, elderly people with the MONW phenotype exhibited a higher risk of CMD and all-cause mortality [27]. In this regard, early identification of MONW individuals would have significant benefits by prompting appropriate risk detection and early management. Higher degree of IR is a representative feature of MONW, using the TyG index might help identifying SCA at risk of developing CMD.

Increased adiposity is rising to a pandemic proportion, it remains a major public health problem globally and it is an important risk factor for hypertension and CMD $[11,12]$. Unfortunately, the prevalence of general and regional increased adiposity has increased in industrialized countries and also in developing countries where there 
is high incidence and prevalence of SCA [13]. NC is an index of upper-body fat deposit, and a reliable, simple, time saving screening measure for identification of individuals, particularly those with small stature but have excess regional body fat distribution. It has been shown to correlate positively with CMD risk factors $[14,15]$ such as BP and serum lipid levels [28, 29], independent of overall adiposity and central obesity [14, 16, 17]. Upperbody fat accumulation has been shown to play a pathogenic role in the development of hypertension and CMD [14-17]. It has been indicated that elevated level of free fatty acid increases oxidative stress, inflammatory and vascular endothelial dysfunction markers, which in turn play significant roles in the development of systemic hypertension [30-32]. Upper-body cutaneous fat has been shown to be responsible for the majority of systemic free fatty acids [33]. It has also been documented that increased NC is a significant predictor of obstructive sleep apnea syndrome [28], which has been associated with fluid retention-related hypertension [34, 35] and poor glycemic control, even at the earliest stages of glucose intolerance [36]. Our finding in this study is in line with evidence from other recent studies that found that measurement of NC might be helpful in early detection of prehypertension in non-obese young adult and obese children [29, 37, 38]. However, our finding was not in accordance with the observation from a recent study in Chinese adults [39]. The finding that TyG-BMI was associated with rHTN in SCA patients further corroborate the importance upper-body fat indicated by $\mathrm{NC}$ in this study.

Association have been reported between increased TG level and endothelial dysfunction linked vasculopathy in SCA patients [40, 41], implying that TG level could have a pathophysiological role in SCA-related complications. More so, elevated TG level has been reported to promote atherothrombotic events in patients with CMD/ type 2 diabetes [42]. Our data however failed to demonstrate an association between TG level and rHTN. Although there was an association between $\mathrm{TyG}$ and rHTN in the binary multivariate regression model, the MODEL 3 of the binary multivariate logistic regression shows that WC has a confounding effect on the association between TyG and rHTN and that the association between TyG and rHTN was dependent on BMI (MODEL 4). We also tested whether the presence of NC could explain the association between TyG and rHTN and it was shown that the association was dependent on NC (MODEL 7). Our results therefore indicate that metabolic risk factors are likely to explain, at least in part, the development of rHTN in SCA.

In SCA patients, blood viscosity is usually lower due to low Hct and $\mathrm{Hb}$ [43], on the other hand, plasma viscosity is known to increase [44] than in the general population. Evidence exists that increased blood viscosity and plasma viscosity increase vascular resistance and BP $[43,44]$. The results in the present study that plasma viscosity but not blood viscosity increased in the rHTN group when compared to the nHTN group may suggest that SCA patients with rHTN could have increase vascular resistance. However, failure to have significant association between rheological parameters and rHTN may rule out the possibility that rheological parameters contribute significantly to the elevated BP in this group of patients. The present study conducted in a group of SCA patients resulted in findings that might not be the unique feature of the SCA patients, but can also be applied to the general population particularly within the same age groups.

\section{Limitation of the study}

1. Although we did not perform radiography to quantify the amount of fat accumulation in the neck directly, the stringent inclusion and exclusion criteria avoided the multiple confounding influences of medication, dietary factor, and lifestyle factor as well as assurance certainty of steady state.

2. The inability to follow up the cohort as a longitudinal study.

\section{Conclusion}

In conclusion, our findings demonstrated for the first time that $\mathrm{NC}$ has a strong independent association with rHTN in SCA patients. Also, TyG index, marker of CMD could also be a useful indicator of rHTN provided $\mathrm{NC}$ is included. The mechanism needs to be further explored in prospective studies. Therefore, these findings clearly underscore exploring $\mathrm{NC}$ as a useful screening utility in early detection and stratification of systemic hypertension, particularly in individuals with SCA.

\section{Abbreviations \\ BP: Blood pressure; CMD: Cardiometabolic disorder; MONW: Metabolically obese but have normal weight; NC: Neck circumference; nHTN: No systemic hypertension; rHTN: Relative systemic hypertension; ROC: Receiver operating characteristic; SCA: Sickle cell anaemia; TyG: Triglyceride-glucose}

\section{Acknowledgements}

Nil

\section{Funding}

The authors have no funding information to disclose.

Availability of data and materials

Other supporting data are available.

Authors' contributions

LAO contributed to the conceptualization and study design, data interpretation, drafting of the manuscript and approval of the final manuscript. OPO

contributed to the data collection and interpretation, drafting of the manuscript and approval of the final manuscript. OMA contributed to the data collection and approval of the final manuscript. ASB contributed to the data collection 
and interpretation and approval of the final manuscript. VAO contributed to the data interpretation, drafting of the manuscript and approval of the final manuscript. AOS contributed to the conceptualization and study design and approval of the final manuscript. All authors read and approved the final manuscript.

\section{Ethics approval and consent to participate}

The study was approved by the Ethical Review. Committees of UITH and LAUTECH Teaching Hospital. All patients were informed about thepurpose and procedures of the study, and gave their written consent. The study was conducted in accordance with the guidelines set by the Declaration of Helsinki on the protection of the rights of human subjects.

\section{Consent for publication}

All patients were informed, and gave consent for the findings of this study to be published.

\section{Competing interests}

The authors declare that they have no competing interests.

\section{Publisher's Note}

Springer Nature remains neutral with regard to jurisdictional claims in published maps and institutional affiliations.

\section{Author details}

${ }^{1}$ HOPE Cardiometabolic Research Team and Department of Physiology, College of Health Sciences, University of Ilorin, P.M.B 1515, Ilorin, Kwara State 240003, Nigeria. ${ }^{2}$ Department of Medicine, Ladoke Akintola University of Technology, Ogbomoso, Oyo State, Nigeria. ${ }^{3}$ Department of Haematology and Blood Transfusion, College of Health Sciences, University of Ilorin, P.M.B 1515, Ilorin, Kwara State 240003, Nigeria. ${ }^{4}$ Department of Ophthalmology, University of Ilorin Teaching Hospital, P.M.B 1515, Ilorin, Kwara State 240003 Nigeria.

Received: 10 November 2017 Accepted: 12 February 2018 Published online: 16 February 2018

\section{References}

1. Potoka KP, Gladwin MT. Vasculopathy and pulmonary hypertension in sickle cell disease. Am J Physiol Lung Cell Mol Physiol. 2015;308:L314-24.

2. Gordeuk VR, Sachdev V, Taylor J, Gladwin MT, Kato G, Oswaldo L. Castro relative systemic hypertension in patients with sickle cell disease is associated with risk of pulmonary hypertension and renal insufficiency. Am J Hematol. 2008;83(1):15-8.

3. Gladwin MT, Barst RJ, Castro OL, Gordeuk VR, Hillery CA, Kato GJ, Kim-Shapiro DB, Machado R, Morris CR, Steinberg MH, Vichinsky EP. Pulmonary hypertension and NO in sickle cell. Blood. 2010;116:852-4.

4. Pegelow $\mathrm{CH}$, Colangelo L, Steinberg M, Wright EC, Smith J, Phillips G, Vichinsky E. Natural history of blood pressure in sickle cell disease: risks for stroke and death associated with relative hypertension in sickle cell anemia. Am J Med. 1997;102(2):171-7

5. Oguanobi NI, Onwubere BJC, Ibegbulam OG, Ike SO, Anisiuba BC, Ejim EC, Agwu O. Arterial blood pressure in adult Nigerians with sickle cell anemia. J Cardiol. 2010;56:326-31.

6. Rodgers GP, Walker EC, Podgor MJ. Is "relative" hypertension a risk factor for vaso-occlusive complications in sickle cell disease? Am J Med Sci. 1993:305:150-6.

7. Gladwin MT, Schechter AN, Ognibene FP, et al. Divergent nitric oxide bioavailability in men and women with sickle cell disease. Circulation. 2003;107:271-8

8. Nath KA, Katusic ZS, Gladwin MT. The perfusion paradox and vascular instability in sickle cell disease. Microcirculation. 2004;11(2):179-93.

9. Ohene-Frempong K, Weiner SJ, Sleeper LA, et al. Cerebrovascular accidents in sickle cell disease: rates and risk factors. Blood. 1998;91:288-94.

10. World Health Organization (WHO). Global status report on noncommunicable diseases 2014. Geneva. Switzerland: World Health Organization; 2014.

11. Lobstein T, Frelut ML. Prevalence of overweight among children in Europe. Obes Rev. 2003:4(4):195-200.

12. Cornier MA, Despr'es JP, Davis N, et al. Assessing adiposity: a scientific statement from the American Heart Association. Circulation. 2011;124(18):1996-2019.
13. Fleming AF, Storey J, Molineaux L, Iroko EA, Attai ED. Abnormal haemoglobins in the Sudan savanna of Nigeria. I. Prevalence of haemoglobins and relationships between sickle cell trait, malaria and survival. Ann Trop Med Parasitol. 1979:73(2):161-72.

14. Preis SR, Massaro JM, Hoffmann U, D'Agostino RB Sr, Levy D, Robins SJ, Meigs JB, Vasan RS, O'Donnell CJ, Fox CS. Neck circumference as a novel measure of cardiometabolic risk: the Framingham heart study. J Clin Endocrinol Metab. 2010;95(8):3701-10.

15. Liang J, Teng F, Li Y, Liu X, Zou C, Wang Y, Li H, Qi L. Neck circumference and insulin resistance in Chinese adults: the Cardiometabolic risk in Chinese (CRC) study. Diabetes Care. 2003;36(9):e145-6.

16. Liang J, Teng F, Liu X, Zou C, Wang Y, Dou L, Sun Z, Qi L. Synergistic effects of neck circumference and metabolic risk factors on insulin resistance: the Cardiometabolic risk in Chinese (CRC) study. Diabetol Metab Syndr. 2014;6:116.

17. Gomez-Arbelaez D, Camacho PA, Cohen DD, Saavedra-Cortes S, Lopez-Lopez C, Lopez-Jaramillo P. Neck circumference as a predictor of metabolic syndrome, insulin resistance and low-grade systemic inflammation in children: the ACFIES study. BMC Pediatr. 2016;16:31.

18. Guerrero-Romero F, Simental-Mendia LE, Gonzalez-Ortiz M, MartinezAbundis E, Ramos-Zavala MG, Hernandez-Gonzalez SO, et al. The product of triglycerides and glucose, a simple measure of insulin sensitivity. Comparison with the euglycemic hyperinsulinemic clamp. J Clin Endocrinol Metab. 2010:95:3347-51.

19. Lee $\mathrm{SH}$, Han K, Yang HK, Kim MK, Yoon KH, Kwon HS, et al. Identifying subgroups of obesity using the product of triglycerides and glucose: the Korea National Health and nutrition examination survey, 2008-2010. Clin Endocrinol. 2015:82:213-20.

20. Holland WL, Brozinick JT, Wang LP, Hawkins ED, Sargent KM, Liu Y, et al. Inhibition of ceramide synthesis ameliorates glucocorticoid-, saturated-fatand obesity-induced insulin resistance. Cell Metab. 2007;5:167-79.

21. DeFronzo RA. Insulin resistance, lipotoxicity, type 2 diabetes and atherosclerosis: the missing links. Diabetologia. 2010;53:1270-87.

22. Mohamed AA, Al-Qurashi F, Whitford DL. Does sickle cell disease protect against diabetes mellitus? Cross-sectional study. Sultan Qaboos University Med J. 2015:Vol. 15(Iss. 1):e116-9.

23. Mohapatra MK. Type 1 diabetes mellitus in homozygous sickle cell anaemia. J Assoc Physicians India. 2005:2005(53):895-6.

24. Ruderman NB, Schneider SH, Berchtold P. The 'metabolically-obese,' normal weight individual. Am J Clin Nutr. 1981;34:1617-21.

25. Meigs JB, Wilson PW, Fox CS, Vasan RS, Nathan DM, Sullivan LM, et al. Body mass index, metabolic syndrome, and risk of type 2 diabetes or cardiovascular disease J Clin Endocrinol Metab 2006:91:2906-12

26. Lee $\mathrm{SH}, \mathrm{Ha} \mathrm{HS}$, Park YJ, Lee $\mathrm{JH}$, Yim HW, Yoon KH, et al. Identifying metabolically obese but normal-weight (MONW) individuals in a nondiabetic Korean population: the Chungju metabolic disease cohort (CMC) study. Clin Endocrinol. 2011:75:475-81.

27. Choi KM, Cho HJ, Choi HY, Yang SJ, Yoo HJ, Seo JA, et al. Higher mortality in metabolically obese normal-weight people than in metabolically healthy obese subjects in elderly Koreans. Clin Endocrinol. 2013;79:364-70.

28. Onat A, Hergenç G, Yüksel H, Can G, Ayhan E, Kaya Z, Dursunoğlu D. Neck circumference as a measure of central obesity: associations with metabolic syndrome and obstructive sleep apnea syndrome beyond waist circumference. Clin Nutr. 2009:28:46-51.

29. Kurtoglu S, Hatipoglu N, Mazicioglu MM, Kondolot M. Neck circumference as a novel parameter to determine metabolic risk factors in obese children. Eur J Clin Investig. 2012;42:623-30.

30. Stojiljkovic MP, Lopes HF, Zhang D, Morrow JD, Goodfriend TL, Egan BM. Increasing plasma fatty acids elevates F2-isoprostanes in humans: implications for the cardiovascular risk factor cluster. J Hypertens. 2002;20:1215-21.

31. Piro S, Spampinato D, Spadaro L, Oliveri CE, Purrello F, Rabuazzo AM. Direct apoptotic effects of free fatty acids on human endothelial cells. Nutr Metab Cardiovasc Dis. 2008;18:96-104

32. Stojiljkovic MP, Zhang D, Lopes HF, Lee CG, Goodfriend TL, Egan BM. Hemodynamic effects of lipids in humans. Am J Physiol Regul Integr Comp Physiol. 2001;280:R1674-9.

33. Nielsen S, Guo Z, Johnson CM, Hensrud DD, Jensen MD. Splanchnic lipolysis in human obesity. J Clin Invest. 2004:113:1582-8.

34. Redolfi S, Yumino D, Ruttanaumpawan P, Yau B, Su MC, Lam J, et al. Relationship between overnight rostral fluid shift and obstructive sleep apnea in nonobese men. Am J Respir Cirt Care Med. 2009;179:241-6. 
35. Grote L, Hedner J, Peter JH. Sleep-related breathing disorder is an independent risk factor for uncontrolled hypertension. J Hypertens, 2000;18:679-85.

36. Steiropoulos P, Papanas N, Bouros D, Maltezos E. Obstructive sleep apnea aggravates glycemic control across the continuum of glucose homeostasis. Am J Respir Crit Care Med. 2010;182:286.

37. Min HJ, Park AY, Kim da H, Lee JG, Park S, Cho HJ. Neck circumference and lowest oxygen saturation are independently associated with high coexistence of hypertension in obstructive sleep apnea. Yonsei Med J. 2014;55(5):1310-7.

38. Kuciene R, Dulskiene V, Medzioniene J. Association of neck circumference and high blood pressure in children and adolescents: a case-control study. BMC Pediatr. 2015;15:127.

39. Liang J, Wang Y, Dou L, Li H, Liu X, Qiu Q, Qi L. Neck circumference and preheypertension: the Cardiometabolic risk in Chinese (CRC) study. J Hypertens. 2015;33:275-8.

40. Zorca S, Freeman L, Hildesheim M, et al. Lipid levels in sickle-cell disease associated with haemolytic severity, vascular dysfunction and pulmonary hypertension. Br J Haematol. 2010;149:436-45.

41. Yuditskaya S, Tumblin A, Hoehn GT, et al. Proteomic identification of altered apolipoprotein patterns in pulmonary hypertension and vasculopathy of sickle cell disease. Blood. 2009:113:1122-8.

42. Krentz AJ. Lipoprotein abnormalities and their consequences for patients with type 2 diabetes. Diabetes Obes Metab. 2003:5(Suppl 1):S19-27.

43. Lamarre $\mathrm{Y}$, Hardy-Dessources MD, Romana M, et al. Relationships between systemic vascular resistance, blood rheology and nitric oxide in children with sickle cell anemia or sickle cell-hemoglobin C disease. Clin Hemorheol Microcirc. 2014;58(2):307-16.

44. Johnson CS. Arterial blood pressure and hyperviscosity in sickle cell disease. Hematol Oncol Clin North Am. 2005;19:827-37.

\section{Submit your next manuscript to BioMed Central and we will help you at every step:}

- We accept pre-submission inquiries

- Our selector tool helps you to find the most relevant journal

- We provide round the clock customer support

- Convenient online submission

- Thorough peer review

- Inclusion in PubMed and all major indexing services

- Maximum visibility for your research

Submit your manuscript at www.biomedcentral.com/submit

) Biomed Central 